\title{
Break-Even Analysis on the Charging and Battery-Swapped Station of Electric Vehicles
}

\author{
Xiaolei $\mathrm{Li}^{1}$, Huawei $\mathrm{Jia}^{2}$ \\ ${ }^{1}$ Henan Electric Power Corporation, Zhengzhou, China; ${ }^{2}$ Xinmi Power Supply Bureau, ZhengZhou, China. \\ Email: lxlhnxm@126.com
}

Received 2013

\begin{abstract}
The construction of electric vehicle charging station plays an important role in the development of electric vehicles and the promotion of the renewable resource. In the paper, a model to analyze the economic benefit of the charging station is presented, which is based on the break-even theory. Then the threshold price is calculated based on the model according to the construction plans of charging facilities in one district. Finally, the strategy for the development of charging faculties is proposed to improve the health growth of electric automotive industry.
\end{abstract}

Keywords: Electric Vehicle; Charging Station; Break-Even; Critical Charging Price

\section{Introduction}

With the global climate issues and the development of renewable energy, a new round of global energy revolution of clean energy and smart grid is rising. Electric vehicle $(E V)$ is a promising way to reduce the energy consume and carbon emission. In addition, it can alleviate the fundamental dependence on oil and the pressure on energy conservation. Currently, the world automotive industry is actively engaged in the developing and promoting process of electric vehicles. Governments and enterprises all over the world have made a great deal of effort in the field of EV[1-4]. And now the development of $\mathrm{EV}$ has been supported by many governments. In China, Beijing, Shanghai, Zhejiang, Shandong and other provinces have made many strategies to promote the construction of charging stations. The State Grid Corporation of China (SGCC) plans to build inter-city smart charging networks for electric vehicles power service in the area of around Bohai bay and Yangtze River Delta.

In China, the construction of charging station is still in its pilot stage. At this stage, our major tasks should focus on the exploring a road of sustainable development through charging station layout planning, pilot construction, commercial operations, profit model analysis, etc.

\section{Conclusions}

\subsection{Break-even Theory}

Break-even analysis is a technique for which identifying the point where the total revenue is just sufficient to cover the total cost. The break-even point (BEP) is the point at which cost or expenses and revenue are equal: there is no net loss or gain, and one has "broken even". As we know, various issues will affect the profit of an investment action, when the changing of these factors reaches a critical value, it will make people hard to choice. Break-even analysis is to find this critical value. Determining the capacity of investment with variable factors, it can provide a basis for decision-making [5-10].

As the investment and operation of charging station have potential losses, we can use break-even analysis to find the critical charging price in different computing environment. In the calculation, the time value of money is not takes into account.

\subsection{The Break-even Model of Charging Station}

The break-even model of charging station is as follows:

$$
S=I-O U
$$

$S=I-O U S$ represents the net profit within the payback period, $I$ represents the operating income, $O U$ represents the investment and operating expenses.

$$
I=I_{E I}+I_{A}+I_{C}+I_{r}
$$

$I_{F I}$ represents electricity sale income, $I_{A}$ represents business pattern income, and In addition, $I_{C}$ represents the revenue of carbon dioxide emission reduction, $I_{r}$ represents a one-time subsidy for the construction of charging station from governments. 


$$
O U=B+O U_{M}+O U_{w}+O U_{E}
$$

OU represents charging station investment, $B$ represents the total construction cost, $O U_{M}$ represents operating expense including equipment operation and maintenance cost, $O U_{M}$ represents maintenance labor cost, $O U_{E}$ represents power purchase cost (only considered the electricity service, regardless of the battery cost).

When the income equals to the investment, which is reaching the break-even balance, then the time is the payback period. Taking into account the life of the substation equipments, we only analyze the break-even in 20 years.

The break-even model of charging station in the payback period is as follows $(t \leq 20)$ :

$$
\begin{aligned}
& S_{t}=I_{t}-O U_{t}=N_{1} p_{1} t+A t+\frac{2.254 C O}{10000} t \\
& +B r-\left(\frac{E}{20}+\frac{B-E}{t}\right) t-m g t-0.02 E t-N p_{2} t
\end{aligned}
$$

where: $t$ is the payback period (Unit: year);

$S$ is the net nrofit at the nerind of $t$ :

$N$ is amount of purchasing energy per year, $p_{2}$ is the price of it;

$N_{1}$ is electricity sales per year, $N_{1}=N \times \eta$ ( $\eta$ is charging efficiency), $\quad p_{1}$ is the charging price;

$B$ is the total construction cost of charging station, $r$ is the subsidy proportion by governments;

$A$ is the annual income of business pattern;

$C$ is carbon dioxide reduction income;

$E$ is total equipment investment;

$O U_{M}$ is equipment operation and maintenance costs, it equals to the $2 \%$ of $E$;

$m$ is the number of people for the operation and maintenance of charging station, $g$ is per-capita wage;

According to the principle of zero profit, we can calculate the critical charging price at payback period $t$ :

$$
\begin{aligned}
& p_{1}=\frac{1}{N_{1} t}\left(\left(\frac{E}{20}+\frac{B-E}{t}\right) t+(m g+0.02 E \quad t\right. \\
& \left.+N p_{2} t-B r-A t-\frac{2.254 C O}{10000} t\right)
\end{aligned}
$$

Similarly, if given the charging price and the electricity purchasing price, the payback period can be calculated as follows:

$$
t=\frac{B-E-B r}{N_{1} p_{1}+A+\frac{2.254 C O}{10000}-\frac{E}{20}-\left(m g+0.02 E-N p_{2}\right.}
$$

\section{Break-even Analysis of Charging and Battery-swapped Station}

According to the electric vehicle development and the process of charging station planning and the construction, the charging facilities development can be divided into pilot stage, urban transport stage, worry free driving stage, and the break-even sale prices (charging prices) are calculated in three stages. The different characteristics of the three stages are considered in the calculation, such as charging station equipment efficiencies, government subsidies, the construction costs, etc.

\section{1. the Break-even Calculation of Typical Charging Station at the Pilot Stage}

The calculation condition is as follows:

(1) The utilization efficiency of charging station equipment in this stage is 0.3 ;

(2) The standard charging station generally configures 10 chargers and each charger's power is $102 \mathrm{~kW}$. The charging efficiency $\eta$ is 0.85 ;

(3) The costs of the standard charging station is 19 million Yuan, and the equipment investment is about $50 \%$ of the total costs;

(4) The number of people for operation and maintenance is 12 , and the average wage of workers is about 27,000 yuan per year;

(5) The costs of equipment operation and maintenance are $2 \%$ of the equipment investment;

(6) The government subsidies are $15 \%$ of the total costs;

(7) As the carbon dioxide reductive emission income and some other incomes can not be implemented currently, they are not included in the calculation.

According to the different purchase prices such as generation price, $10 \mathrm{kV}$ large industrial price and general commercial price, which is taken from the Development and Reform Commission of Henan province, critical charging prices are calculated in the different payback period of 5 years, 10 years, 15 years and 20 years. The calculated results are shown in Table 1.

The purchase price used 0.727 yuan $(\mathrm{kWh})^{-1}$ to calcu-

\begin{tabular}{|c|c|c|c|}
\hline$t($ years $)$ & 0.3912 & 0.565 & 0.727 \\
\hline 5 & 2.043 & 2.248 & 2.438 \\
\hline 10 & 1.360 & 1.565 & 1.755 \\
\hline 15 & 1.133 & 1.337 & 1.528 \\
\hline 20 & 1.019 & 1.223 & 1.414 \\
\hline
\end{tabular}
late consider of the charging station commercial and social operation. If we take 20 years as the cost recovery period and the equipment utilization is $100 \%$, the lowest

Table 1. the break-even charging price in different payback periodat the pilot stage. 
charging price is calculated as 0.965 yuan $(\mathrm{kWh})^{-1}$. Then we choose 0.9 yuan $\left(\mathrm{kWh}^{-1}\right.$ as a benchmark and increased 0.2 yuan $\left(\mathrm{kWh}^{-1}\right.$ each time, the relationship curve between the payback period and equipment utilization is shown in Figure 1:

\subsection{Break-even Calculation of Typical Battery- swapped Station at the Pilot Stage}

The different calculate conditions between the typical battery-swapped station and the charging station are as follows:

(1) Sales power

The charging energy of battery-swapped station should be calculated based on the average daily mileage and the battery capacity of electric vehicles. According to typical design of battery-swapped station, two battery-swapped positions can swap electric vehicles' battery 100 times a day, and the annual charging energy will reach 1.2 million $\mathrm{kWh}$. In this stage, the equipment utilization factor is 0.3 .

(2) Labor costs

According to the charging station, a typical batteryswapped station with two battery-swapped positions will need 20 persons, for the battery monitoring requires additional staff.

(3) Business model

Unlike the charging station, the battery-swapped station has an extra battery-swapped service. For the convenience of calculation, the service fee is 5 yuan each time temporarily.

According to the different purchase prices such as generation price, $10 \mathrm{kV}$ large industrial price and general commercial price, critical charging prices are calculated in the different payback period of 5 years, 10 years, 15 years and 20 years. The calculated results are shown in Table 2.

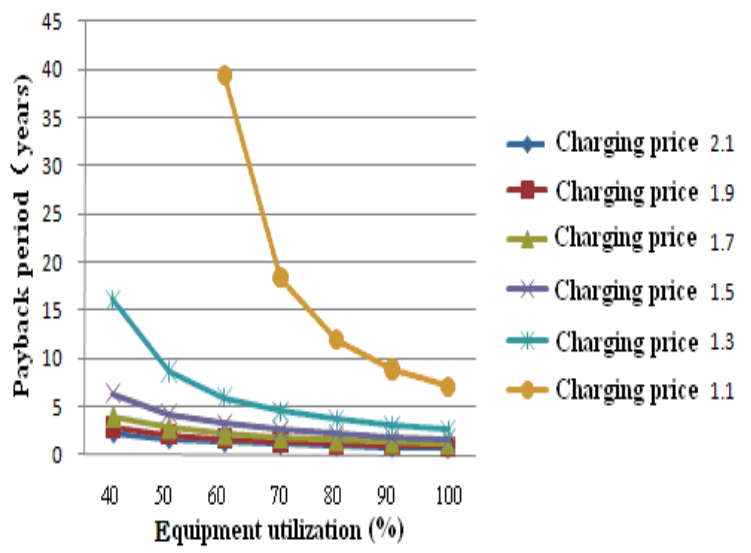

Figure 1. The relationship curve between the payback period and equipment utilization.

\subsection{Break-even Calculation of Typical Charging Station at the Urban Transport Stage}

According to the planning and research of a charging station, urban transport stage electric car ownership has a rapid growth. So the equipment utilization set equal to 0.5 ; at the stage, government's subsidy rate will drop to $10 \%$; the costs of electric vehicle charging stations will be decreased for the technological progress and cost reduction. Construction cost $B_{1}$ will be 15 million yuan.

According to the different purchase prices such as generation price, $10 \mathrm{kV}$ large industrial price and general commercial price, critical charging prices are calculated in the different payback period of 5 years, 10 years, 15 years and 20 years. The calculated results are shown in Table 3.

Table 2. the break-even charging price in the different payback period at the pilot stage.

\begin{tabular}{|c|c|c|c|c|}
\hline$t($ years $)$ & $p_{2}($ yuan $/ \mathrm{kWh})$ & 0.3912 & 0.565 & 0.727 \\
\hline & 5 & 3.760 & 3.965 & 4.155 \\
\hline & 10 & 2.414 & 2.619 & 2.809 \\
\hline & 15 & 1.966 & 2.170 & 2.361 \\
\hline & 20 & 1.741 & 1.946 & 2.137 \\
\hline
\end{tabular}

Table 3. the break-even charging price in the different payback period at the urban transport stage.

\begin{tabular}{ccccc}
\hline & $p_{2(\text { yuan } / \mathrm{kWh})}$ & $\mathbf{0 . 3 9 1 2}$ & $\mathbf{0 . 5 6 5}$ & $\mathbf{0 . 7 2 7}$ \\
\hline 5 & & 1.265 & 1.470 & 1.660 \\
& & 0.923 & 1.127 & 1.318 \\
10 & 0.809 & 1.013 & 1.204 \\
20 & 0.752 & 0.956 & 1.147 \\
\hline
\end{tabular}

The purchase price used 0.727 yuan(kWh) ${ }^{-1}$ to calculate consider of the charging station commercial and social operation. If we take 20 years as the cost recovery period and the equipment utilization is $100 \%$, the lowest charging price is calculated as 0.965 yuan $(\mathrm{kWh})^{-1}$. Then we choose 0.9 yuan $\left(\mathrm{kWh}^{-1}\right.$ as a benchmark and increased 0.2 yuan $(\mathrm{kWh})^{-1}$ each time, the relationship curve between the payback period and equipment utilization is shown in Figure 2:

\subsection{The Break-Even Calculation of Typical Battery- Swapped Station at the Urban Transport Stage}

Compared with the previous stage, this stage we set the 
equipment utilization equal to 0.5 . According to the different purchase prices such as generation price, $10 \mathrm{kV}$ large industrial price and general commercial price, critical charging prices are calculated in the different payback period of 5 years, 10 years, 15 years and 20 years. The calculated results are shown in Table 4.

\subsection{Break-Even Calculation of Typical Charging Station at Worry Free Driving Stage}

According to the planning and construction program of an electric vehicle charging station, at worry free driving stage, the technology of electric vehicles will have been developed, and the structure of power grid has been able to meet the needs of distributed charging, at the stage, the development of charging stations will be the mainstream.

At this stage, the ownership of electric vehicles growth continuously, so set equipment utilization of this stage equal to 0.7 , the construction cost $B_{1}$ will be 12 million yuan; government subsidies will be dropped to $5 \%$. According to the different purchase prices such as generation price, $10 \mathrm{kV}$ large industrial price and general commercial price, critical charging prices are calculated in the different payback period of 5 years, 10 years, 15 years and 20 years. The calculated results are shown in Table 5.

The purchase price used 0.727 yuan $\left(\mathrm{kWh}^{-1}\right.$ to calculate consider of the charging station commercial and social operation. If we take 20 years as the cost recovery period and the equipment utilization is $100 \%$, the lowest charging price is calculated as 0.965 yuan $(\mathrm{kWh})^{-1}$. Then we choose 0.9 yuan $\left(\mathrm{kWh}^{-1}\right.$ as a benchmark and in creased 0.2 yuan $\left(\mathrm{kWh}^{-1}\right.$ each time, the relationship curve between the payback period and equipment utilization is shown in Figure 3.

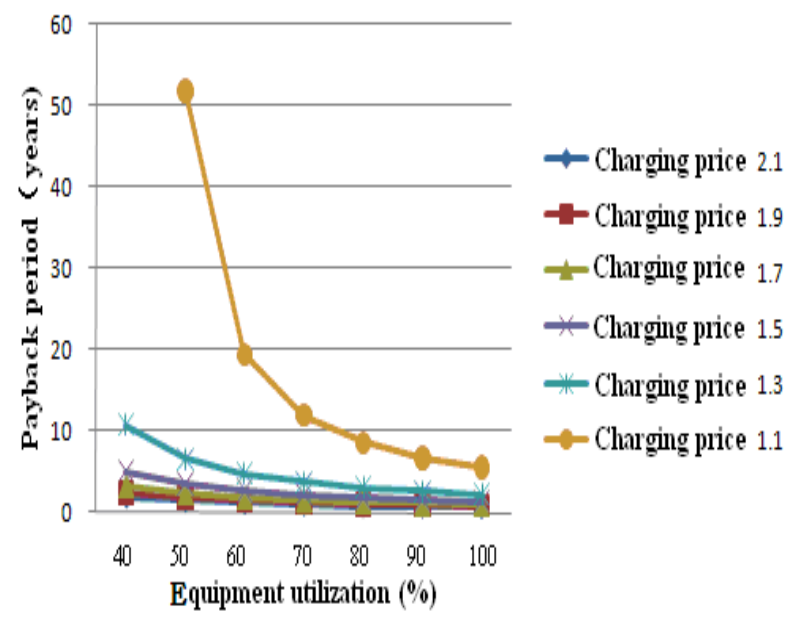

Figure 2. The relationship curve between the payback period and equipment utilization.
Table 4. Break-even charging price in the different payback period at the urban transport stages.

\begin{tabular}{|c|c|c|c|}
\hline$t($ years $) \quad p_{2}($ yuan $/ \mathrm{kWh})$ & 0.3912 & 0.565 & 0.727 \\
\hline 5 & 3.160 & 3.365 & 3.555 \\
\hline 10 & 2.098 & 2.302 & 2.493 \\
\hline 15 & 1.744 & 1.948 & 2.139 \\
\hline 20 & 1.566 & 1.771 & 1.962 \\
\hline
\end{tabular}

Table 5. the break-even charging price in the different payback period at the urban transport stage.

\begin{tabular}{|c|c|c|c|}
\hline$p_{2(\text { yuan } / \mathrm{kWh})}$ & 0.3912 & 0.565 & 0.727 \\
\hline 5 & 0.954 & 1.158 & 1.349 \\
\hline 10 & 0.747 & 0.952 & 1.142 \\
\hline 15 & 0.678 & 0.883 & 1.073 \\
\hline 20 & 0.644 & 0.848 & 1.039 \\
\hline
\end{tabular}

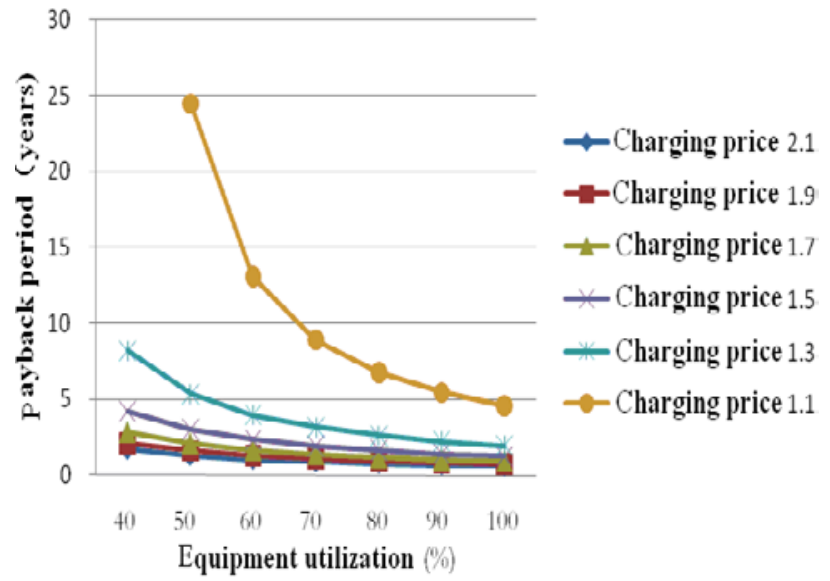

Figure 3. Equipment utilization and investment payback curve.

\section{Conclusions}

At the present time, due to the fewer vehicles, low equipment and weak technological reliability, the construction and operation of the electric vehicle charging station project is at a loss. To ensure the full cost recovery of the charging station and its healthy development, governments need to increase policy support for the electric vehicle charging station, introducing a special charging price and giving preferential treatment in the charge of land and taxation. The operators of charging station should strive to expand the scope and variety of 
services, develop the market to increase revenue. Only in this way can the operation cost of charging station be reduced and the industries of electric vehicles will be thrived.

\section{REFERENCES}

[1] [1] DU Cheng-gang, LI Jin, HU Chao, et al. "Smart Grid Construction Promotes the Rapid Development of Electric Vehicle Industry, "Distribution \& Utilization, vol.27, pp.5-9, 2010.

[2] ZHOU Feng-quan, LIAN Zhan-wei, WANG Xiao-lei, et al. "Discussion on operation mode to the electric vehicle charging station, " Power System Protection and Control, vol.38, pp. 63-66, 2010.

[3] KANG Ji-guang, WEI Zhen-lin, CHENG Dan-ming, et a1. "Research on Electric Vehicle Charging Mode and Charging Stations Construction," Demand Side Management, vol.11, pp.69-71, 2009.

[4] LU Mang, ZHOU Xiao-bing, ZHANG Wei, "Research on Development of Charging Facilities for Electric Vehicles at Home and Abroad, "Central China Electric Power, vol.23, pp. 16-20, 2010.

[5] G.de Kook, K.H.van Donselaar, and T. van Woensel, "A break-even analysis of RFID technology for inventory sensitive to shrinkage," International
Journal of Production Economics, vol. 112, pp. 521-531, 2008.

[6] M. B. Dematawewa and P. J. Berger, "Break-Even Cost of Cloning in Genetic Improvement of Dairy Cattle,” Journal of Dairy Science, vol. 81, pp.1136-1147, 1998.

[7] Hayes and M.E.Goddard, "Break-even cost of genotyping genetic mutations affecting economic traits in Australian pig enterprises," Livestock Production Science, vol. 89, pp. 235-242, 2004.

[8] L.John D," Break-even analysis: a useful management tool in the lodging industry," International Journal of Hospitality Management, vol. 2, pp. 115-120, 1983.

[9] S. L. Keas, E. Jacobs, D. Harrison, K. Farmer, and D. Thompson, "Future economic outlook of Nebraska rural community pharmacies based on break-even analysis of community operational costs and county population,” Research in Social and Administrative Pharmacy, vol. 6, pp. 209-220.

[10] N. S. Kim and B. Van Wee, "The relative importance of factors that influence the break-even distance of inter-modal freight transport systems," Journal of Transport Geography, vol. 19, pp. 859-875. 